\title{
ASPECTOS MORFOLÓGICOS DE FRUTOS, SEMENTES, GERMINAÇÃO E PLÂNTULAS DE DUAS ESPÉCIES FLORESTAIS DAAMAZÔNIA. I. Dinizia excelsa DUCKE (ANGELIM- PEDRA). II Cedrelinga catenaeformis DUCKE (CEDRORANA) - LEGUMINOSAE: MIMOSOIDEAE ${ }^{1}$
}

\author{
MARIADE FÁTIMAFIGUEIREDO MELO², VÂNIAPALMEIRAVARELA ${ }^{3}$
}

\begin{abstract}
RESUMO - As duas espécies selecionadas para o presente trabalho são nativas da floresta de terra firme da Amazônia, apresentam interesse econômico e grande carência de informações referentes aos aspectos morfológicos da germinação. Este estudo aborda as características morfológicas de frutos, sementes e plântulas de Cedrelinga catenaeformis Ducke e Dinizia excelsa Ducke, além do tipo de germinação, evidenciando a morfologia dos vários estádios de desenvolvimento da planta, iniciando-se com a protrusão da raiz até a formação de plântula normal, com a emissão dos primeiros protófilos. Os estudos para ambas as espécies foram conduzidos no laboratório de semente do INPA/CPST. Os testes de germinação foram realizados na temperatura de $25^{\circ} \mathrm{C}$, em bandejas plásticas de $30 \times 20 \times 5 \mathrm{~cm}$, com 50 sementes para cada espécie, utilizando-se como substrato vermiculita. Os frutos de C. catenaeformis e D. excelsa são legumes samaróides e longos. As sementes são suborbiculares, com bordo irregular em C. catenaeformis e oblongas e achatadas em D. excelsa .Ambas as espécies apresentaram germinação do tipo epígea e fanerocotiledonar. As plântulas de $C$. catenaeformis caracterizam-se pelos eófilos bifoliolados, opostos, enquanto $D$. excelsa apresenta eófilos pinados
\end{abstract}

Termos para indexação: Amazônia Central, espécies nativas, morfologia.

\section{MORPHOLOGICALASPECTS OF FRUITS, SEEDS, GERMINATIONAND SEEDLINGS OF TWO AMAZONIAN TIMBER SPECIES. I. Dinizia excelsa DUCKE (ANGELIM-PEDRA). II. Cedrelinga catenaeformis DUCKE (CEDRORANA) - LEGUMINOSAE: MIMOSOIDEAE.}

\begin{abstract}
The two timber species in this study are native to the Amazonian non-flooded forest. Although they are of great economic interest there is little information regarding the morphological aspects of their seed germination. The present study addresses the morphological characteristics of fruits, seeds and seedlings of Cedrelinga catenaeformis Ducke and Dinizia excelsa Ducke. Furthermore, it reports on their type of germination showing aspects of the morphology at various stages of the plant's development, from radicle protrusion to normal seedling, development with the emergence of the first foliage leaves. The studies on both species were carried out in the seed laboratory at INPA/CPST. Germination tests were performed at $25^{\circ} \mathrm{C}$, in $30 \times 20 \times 5 \mathrm{~cm}$ plastic trays with 50 seeds of each species using vermiculite as substrate. The data obtained in the present study aim to facilitate the recognition of these species in the field, contributing to the morphological aspects of seeds, germination and seedlings.
\end{abstract}

Index terms: Central Amazonian, native species, morphology.

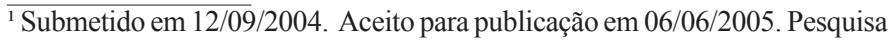
financiada pela FAPEAM (www.fapeam.am.gov.br);

${ }^{2,3}$ Pesquisadores do Instituto Nacional de Pesquisas da Amazônia - INPA/
}

Botânica/Silvicultura Tropical, Av. André Araújo, 2936; 69.083-000, Manaus -AM; ffmelo@inpa.gov.br; vaniav@inpa.gov.br. 


\section{INTRODUÇÃO}

As duas espécies selecionadas para o presente trabalho são florestais nativas, apresentam interesse econômico e grande carência de informações referentes aos aspectos morfológicos da germinação. Dinizia excelsa Ducke, da família Leguminosae, é conhecida vulgarmente como angelim-pedra, possui madeira empregada na fabricação de chapas decorativas, dormentes, construção civil e naval, macetas, marcenaria, carpintaria, sendo ainda resistente ao ataque de fungos e térmitas. Cedrelinga catenaeformis Ducke pertencente à família Leguminosae, ocorrendo nos estados do Amazonas e Pará, sua madeira é utilizada em carpintaria, construção civil e naval, celulose e papel, móveis baratos e caixas (Loureiro et al., 1979).

A intensificação do uso de espécies florestais comerciais, que vem ocorrendo na Amazônia nas últimas décadas, impõe a necessidade de estudos sobre a germinação de semente dessas espécies, com a finalidade de fornecer subsídios para sua propagação, cujos objetivos seriam tanto a preservação quanto a utilização dessas plantas com os mais variados interesses.

Os estudos direcionados ao conhecimento específico dos aspectos morfológicos de germinação de sementes de uma espécie, além de contribuir em sua propagação, tornam-se fundamentais para o melhor planejamento e tratamento silvicultural das espécies, permitindo o uso racional da floresta. O conhecimento morfológico da plântula permite caracterizar famílias, gêneros e até mesmo espécies e tem sido aplicado no inventário florestal de regiões de clima temperado e tropical (Ferraz, 1991; Oliveira, 1993).

Dentro da Tecnologia e Análise de Sementes Florestais, a interpretação do teste de germinação é importante para o conhecimento da morfologia dos vários estádios de desenvolvimento da plântula, caracterizando a plântula normal para cada espécie. No teste de germinação, de acordo com as Regras para Análise de Sementes (Brasil, 1992), considera-se germinada toda semente que pela emergência e desenvolvimento das estruturas essenciais de seu embrião, demonstra aptidão para produzir uma planta normal sob condições normais e favoráveis de campo.

O estudo de morfologia de plântulas é importante, pois contribui para o conhecimento morfo-anatômico integral da espécie, oferecendo quantidade de caracteres próprios que torna possível determinar a espécie da qual procede a semente, sendo também utilizada em laboratórios de análise de sementes para identificar plântulas normais e anormais (Oliveira, 1988).

Os trabalhos de morfologia de sementes e plântulas são importantes, também, para auxiliar na identificação de espécies em estudos de regeneração natural de áreas degradadas. Estudos morfológicos das fases do desenvolvimento pósseminal de cedro (Cedrela odorata L.) foram efetuados por Andrade e Pereira (1994). Estes autores abordaram a descrição das plântulas anormais, que poderá auxiliar na identificação destas em testes de germinação, conduzidos em laboratórios de análises de sementes.

Em geral, os estudos sobre a morfologia dos estádios de desenvolvimento de plântulas abordam a classificação da germinação, em relação à posição dos cotilédones quanto ao nível do solo. A germinação é denominada de epígea, quando os cotilédones se elevam acima do nível do solo, e hipógea, quando permanecem enterrados até o final do processo de formação da plântula (Carvalho e Nakagawa, 1988; Andrade e Damião Filho, 1989; Oliveira, 1993).

As plântulas podem ser classificadas em fanerocotiledonar ou criptocotiledonar e se referem à liberação ou não dos cotilédones do tegumento da semente. Nas plântulas fanerocotiledonares os cotilédones saem por completo do tegumento, e nas criptocotiledonares estes permanecem envolvidos pelo tegumento Ducke (1965).

Estudos sobre metodologia e teste de germinação, dando ênfase às descrições da plântula normal e anormal, contribuem na interpretação e padronização do teste através do conhecimento de cada espécie. Apesar da grande importância de estudos morfológicos de plântulas, os trabalhos específicos com as espécies florestais da Amazônia são praticamente inexistentes.

Em face da potencialidade apresentada pela D. excelsa e C. catenaeformis, este trabalho teve como objetivo descrever as características morfológicas de frutos, sementes, germinação e plântulas de forma a fornecer subsídios para inclusão dessas espécies em futuros manuais técnicos.

\section{MATERIAL E MÉTODOS}

Os frutos de angelim-pedra (D. excelsa) utilizados neste estudo foram coletados de uma árvore matriz localizada no Campus III do INPA, cuja frutificação ocorreu em 8/3/03. Após a coleta dos frutos no chão, procedeu-se a extração manual das sementes.

Os frutos de cedrorana (C. catenaeformis) foram coletados no dia 20/02/2004 no Campus do INPA-Aleixo I, pertencente ao Instituto de Pesquisas da Amazônia, ManausAM. Após a coleta efetuou-se a extração manual das sementes.

Até o início dos ensaios da germinação, as sementes de angelim-pedra (D. excelsa) foram mantidas, por sete meses, 
em frascos hermeticamente fechados, em câmara de armazenamento à temperatura de $15^{\circ} \mathrm{C}$. Antes da instalação dos testes de germinação, as sementes foram tratadas com imersão em ácido sulfúrico por 20 minutos para superar a dormência, conforme recomendação de Vastano Jr. et al. (1983).

Os testes de germinação das sementes de cedrorana foram realizados imediatamente após a coleta dos frutos.

Os estudos para ambas as espécies foram conduzidos no laboratório de análise de semente do INPA/CPST, sendo as avaliações morfológicas para descrição das plântulas realizadas na Coordenação de Pesquisas em Botânica/CPBO. As sementes foram colocadas para germinar em câmaras de marca FANEM, com fotoperíodo de 12 horas (luz:escuro), providas de lâmpada fluorescente de luz branca fria e fluxo luminoso de aproximadamente $10 \mu \mathrm{mol} \cdot \mathrm{m}^{-2} \cdot \mathrm{s}^{-1}$ de radiação PAR (radiação fotossinteticamente ativa). Os testes de germinação foram realizados na temperatura de $25^{\circ} \mathrm{C}$, em bandejas plásticas de $30 \times 20 \times 5 \mathrm{~cm}$, com 50 sementes para cada espécie, utilizando-se como substrato vermiculita. Foi considerada germinação o período de intumescimento da semente até a abertura dos cotilédones. As observações em dias alternados permitiram o acompanhamento detalhado do processo germinativo e a descrição morfológica do desenvolvimento foi realizada em estereomicroscópio, enfatizando os caracteres úteis das identificações das espécies em estudo. As ilustrações foram feitas com auxílio de um estereomicroscópio acoplado a câmara clara, com aumento de até quatro vezes.

Considerou-se como plântula, a fase do desenvolvimento na qual o material se apresentava com raiz, hipocótilo, epicótilo e protófilos (primeiro par de folhas surgido após a abertura dos cotilédones). Analisou-se o tipo de germinação, forma, cor, consistência da raiz, epicótilo, coleto. Observações sobre a filotaxia, textura, forma, ápice, base, margem e pecíolo foram realizadas nos cotilédones e protófilos.

A terminologia usada segue os trabalhos de Rizzini (1965), Ducke (1965), Vogel (1980), Hickey (1973) e Stearn (1983). Os critérios pré-estabelecidos para caracterizar tipos de anormalidade foram baseados em Brasil (1992).

\section{RESULTADOS E DISCUSSÃO}

\section{Dinizia excelsa Ducke}

Morfologia do fruto - o fruto de angelim-pedra é um legume samaróide (Barroso et al., 1999), longo, 17,0-29,5x6,0$8,0 \times 0,2-0,3 \mathrm{~cm}$, plano-compresso, sem constrições, indeiscente, valvas fixas por suturas, com cavidades das sementes indistintamente visíveis, ligeiramente curvado, largamente oblongo, estipitado, ápice e base arredondados, margem inteira, geralmente rugosa com rugas longitudinais, paralelas entre si, sendo uma das margens mais alargadas (aliforme) (Figura 1A). Epicarpo coriáceo, brilhante, castanhoescuro a quase enegrecido, levemente reticulado, glabro, não esfoliante. Mesocarpo ausente. Endocarpo opaco, não septado, castanho, com o local da semente circundado por tecido esponjoso. Sementes até dez, unisseriadas, transversalmente distribuídas ao longo da região mediana do fruto.

Morfologia da semente - a semente de angelim-pedra é estenospérmica, albuminosa, 1,1-1,5x0,4-0,8x0,17-0,5cm, plano-compressa, oblonga, com ápice e base arredondados, margem inteira, com pleurograma e linha divisória ausentes (Figura 1B). Testa de consistência óssea (desidratada), coriácea quando hidratada, homócroma, castanho-escura a quase negra, ornamentada por linhas delgadas, paralelas entre si, levemente curvas, intercaladas por pontuações enegrecidas e brilhantes (Figura 1C), rachadas quando intumescida; borda geralmente mais escura que a superfície, de coloração negra. Região hilar castanho-escura, recoberta por pontuações enegrecidas e brilhantes; hilo subapical, em relação ao ápice da radícula, punctiforme, em depressão, envolvido por borda elevada, enegrecida, não apresentando vestígio funicular (Figura 1D). Lente não observada. Tégmen espesso, coriáceo e de coloração marrom-escura. Endosperma crasso, opaco, limitado, adnato a testa e envolve o embrião (Figura 1E, F). Embrião axial, reto, com eixo embrionário estreito e esbranquiçado. Plúmula rudimentar (Figura 1G). Cotilédones verdes, dominantes, auriculares e ocultando as margens da radícula (Figura 1H).

Morfologia da germinação - o angelim-pedra apresenta germinação epígea, fanerocotiledonar (Figura 1I). O processo de germinação se inicia pelo surgimento da raiz, que rompe o tegumento próximo à região hilar, dois dias após a semeadura. A raiz primária desenvolve-se rapidamente, apresentando-se inicialmente curta, cônica, curva a levemente sinuosa, perolada, glabra. À medida que ocorre seu alongamento, a coifa se diferencia e afunila, de coloração castanha. As raízes secundárias surgem simultaneamente com desprendimento do tegumento, apresentam-se muito delgadas com poucas ramificações, irregularmente distribuídas ao longo da raiz primária (Figura 1I). Coleto distinto, anular, espessado, perolado e glabro. Hipocótilo epígeo, longo, em relação ao epicótilo, cerca de $9,0 \mathrm{~cm}$ de comprimento, herbáceo, anguloso, levemente canaliculado, delgado, pubérulo, esbranquiçado na base e esverdeado em direção ao ápice 

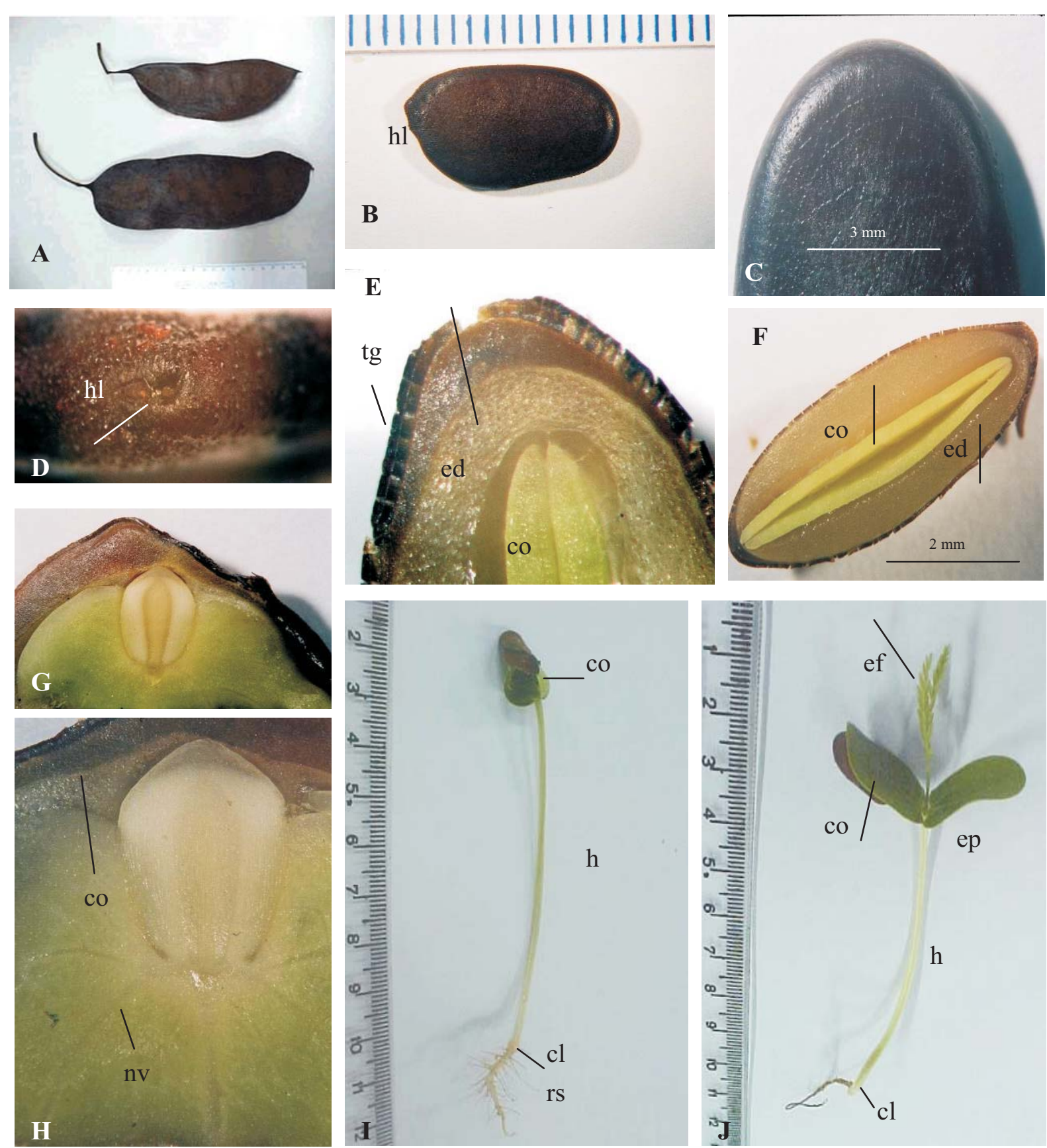

FIGURA 1. Caracterização morfológica do fruto, semente, germinação e plântula de Dinizia excelsa Ducke. A-fruto desidratado; B - semente desidratada; $C$ - detalhe da testa desidratada; D-região hilar-hilo em depressão; $\mathbf{E}$ - semente em corte longitudinal F -tégmen, endosperma e cotilédones em corte transversal -; G - detalhe do eixo hipocótilo-radícula; H detalhe dos cotilédones; $I$ - detalhe da raiz secundária, hipocótilo e cotilédones liberando-se do tegumento; $J$-plântula normal - detalhe do coleto, cotilédones e primeiros eófilos. rs - raiz secundária; cl - coleto; h - hipocótilo; co cotilédones; pl-plúmula; tg - tégmen; ed-endosperma; ef-eófilos; hl-hilo; nv-nervura.

(Figura 1I). Cotilédones opostos, foliáceos, isófilos, verdeescuros, oblongos, livres, sésseis, membranáceos, com ápice arredondado, margem inteira a levemente irregular, base espessa, fendida, de coloração creme-esverdeada, de onde partem três nervuras (Figura 1H), a central de maior tamanho e terminando próxima ao ápice, e as duas laterais de menor tamanho, alcançando até a metade do comprimento das lâminas cotiledonares.

Morfologia de plântula - a plântula de angelim-pedra apresenta sistema radicular axial ou pivotante. A raiz primária 
permanece mais ou menos do mesmo tamanho da raiz descrita na fase de germinação, com $3-4 \mathrm{~cm}$ de comprimento, mais espessa na base, afunilando-se em direção ao ápice, levemente sinuosa, sub-lenhosa, glabra e de coloração castanha. Raízes secundárias delgadas, castanho-escuras, glabras, distribuídas irregularmente e menores do que a raiz primária. Coleto cilíndrico, espessado, sub-herbáceo, anular, glabro e de coloração castanha. Hipocótilo, epígeo, reto, anguloso, subherbáceo, longo, castanho-escuro, glabro e canaliculado lateralmente. Cotilédones geralmente persistentes com características semelhantes as da germinação (Figura 1J). Nó cotiledonar circular e glabro. Epicótilo curto, em relação ao hipocótilo, com $1,7 \mathrm{~cm}$ de comprimento, reto, herbáceo, semicilíndrico, verde, recoberto por tricomas simples, esparsos, diminutos, curvados, hialinos. Eófilos dois, compostos, opostos, paripinados, com sete pares de folíolos sub-opostos, sésseis, ovais, ápice obtuso, margem ciliada, base oblíqua, glabra na face adaxial, pubérula na nervura principal da face abaxial; venação broquidódroma (Figura 1J). Raque curta, $2,0-2,5 \times 0,7-0,8 \mathrm{~cm}$, semi-cilíndrica, canaliculada na face adaxial, com tricomas simples, curvos, diminutos hialinos. Pecíolo delgado, aproximadamente $0,5 \mathrm{~cm}$ de comprimento, semicilíndrico, canaliculado, com tricomas semelhantes aos encontrados na raque.

\section{Cedrelinga catenaeformis Ducke}

Morfologia do fruto - o fruto de cedrorana é um legume samaróide (Barroso et al., 1999), 9,0-12,0x2,0-3,0x0,1-0,9cm, indeiscente, monospérmico, pêndulo, formando cadeia longa constituída por dois ou mais legumes. Os pontos de inserção entre os legumes são torcidos, em espaços regulares, facilmente descartáveis, ao longo do fruto. Legume oblongoelíptico, plano-compresso, de margem inteira a semi-revoluta, às vezes sinuosa, verde quando imaturo, creme a amarelo pardacento quando maduro, cartáceo e glabro. Valvas indeiscentes, suturas evidentes, com cavidade da semente distintamente visível (Figura 2A). Epicarpo opaco, amarelo pardacento, áspero e reticulado. Mesocarpo ausente. Endocarpo plano, amarelo pardacento na região em torno da semente e de coloração marrom na área septada que abriga a semente. Semente única, localizada na região mediana do fruto.

Morfologia da semente - a semente de cedrorana é estenospérmica, 2,5-3,9x1,4-1,8x0,32-0,59cm, exalbuminosa, com pleurograma e linha fraturada ausentes. Semente oblonga a suborbicular, com base e ápice arredondados (Figura 2B), superfície verde e lisa, quando hidratada, rugosa e marrom quando desidratada, região central proeminente, descendo em direção ao bordo; testa lisa, brilhante, de consistência membranácea (hidratada), cartácea (desidratada), heterócroma, verde com bordo marrom; bordo irregular, cristado, verrucoso, de consistência carnosa (Figura 2C). A testa desprende-se facilmente quando hidratada. Região hilar proeminente, castanho-clara, com hilo punctiforme, marginal, subapical e de coloração castanha; funículo persistente, filiforme, visível sem auxílio de estereomicroscópio, sinuoso, da mesma coloração da região hilar (Figura 2D). Eixo embrionário de ligeiramente inclinado a reto (Figura 2E). Cotilédones plano-convexos, carnosos (Figura 2E, F) com uma incisão basal cerca de $0,5 \mathrm{~cm}$ de comprimento, verdes, dominantes, oblongos, com ápice arredondado e margem inteira; eixo hipocótilo-radícula espesso, amarelado, plúmula bem diferenciada, apresentando os primórdios foliares bem delimitados (Figura 2E).

Morfologia da germinação - a germinação de cedrorana é epígea, fanerocotiledonar, com emergência da radícula inicialmente curva e posteriormente levemente sinuosa. $\mathrm{O}$ processo da germinação inicia-se pelo intumescimento da semente que aumenta de volume e três dias após a semeadura ocorre a protrusão da radícula (Figura 2B). Raiz primária inicialmente cilíndrica, curta, glabra, de coloração creme, a medida que ocorre seu alongamento, a base torna-se mais espessa, afunilando-se em direção a coifa de coloração castanha (Figura 2G). Coleto evidente, cilíndrico, glabro, herbáceo, espesso, de verde-esbranquiçado a verde-amarelado. Hipocótilo epígeo, inicialmente curvo, curto, posteriormente ereto, herbáceo, cilíndrico e pubérulo ao longo de sua extensão. Cotilédones carnosos, glabros, isófilos, oblongos, subsésseis, verde-claros, convexos, opostos, unidos lateralmente, ápice arredondado, base fendida a sub-cordada, margem inteira a levemente irregular, com tegumento da semente persistente na face abaxial (Figura 2G).

Morfologia da plântula normal - plântula de cedrorana com sistema radicular pivotante, cilíndrica, sublenhosa, base espessa, de coloração creme, tornando-se delgada na região apical, sinuosa e de coloração castanha (Figura 2H, I); raízes secundárias curtas, cônicas, irregularmente distribuídas. Coleto evidente, espessado, cilíndrico, esbranquiçado e glabro (Figura 2H). Hipocótilo epígeo, reto a sinuoso, cilíndrico, verde (Figura 2I), com estrias longitudinais, pubérulo, tricomas diminutos, simples, hialinos e raramente bífidos. Cotilédones em geral persistentes, com as mesmas características encontradas na fase de germinação (Figura 2I). Nó cotiledonar espesso, elíptico, glabro e de coloração creme. Epicótilo longo, em relação ao hipocótilo, variando entre 4,5 e $6,2 \mathrm{~cm}$ de comprimento, herbáceo, de coloração verde, semicilíndrico, 

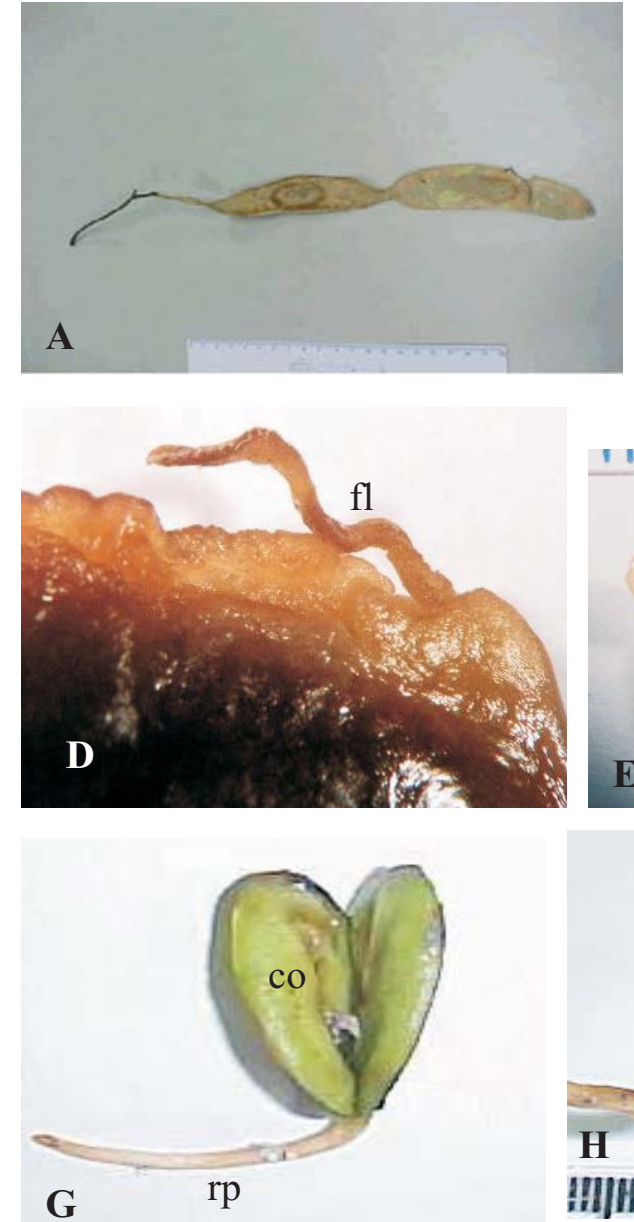

$\mathbf{H}$

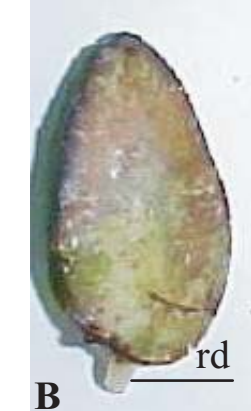

B
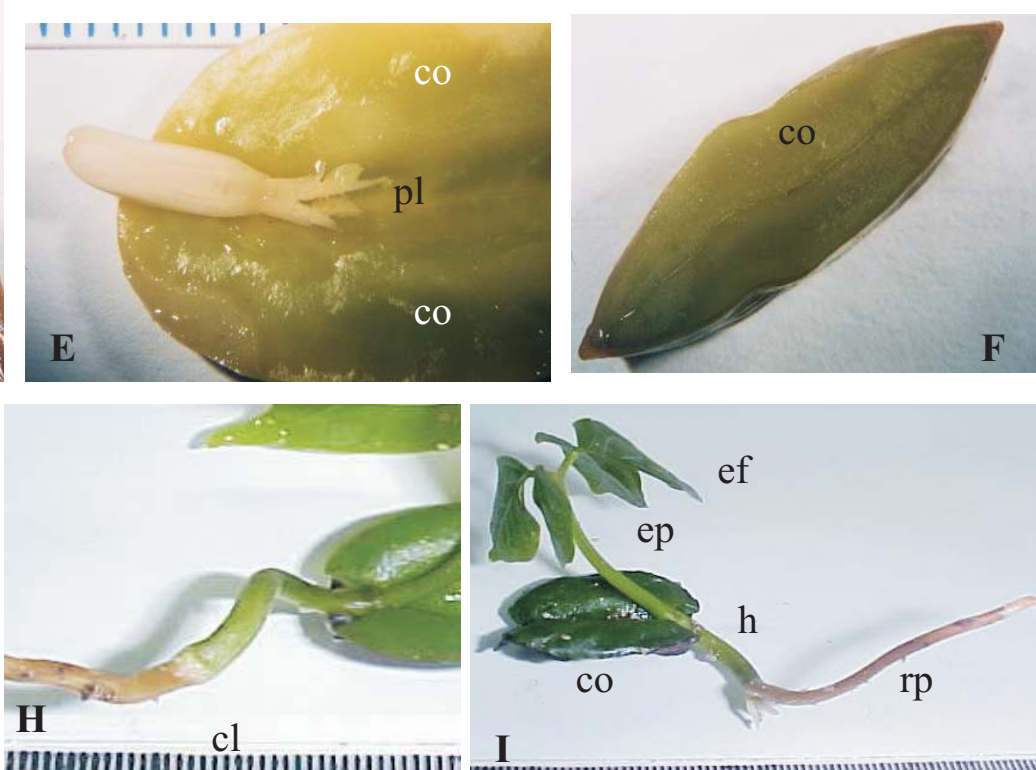

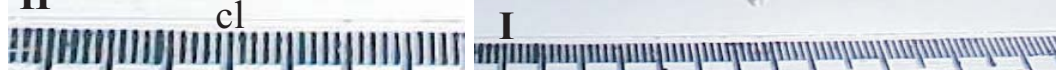
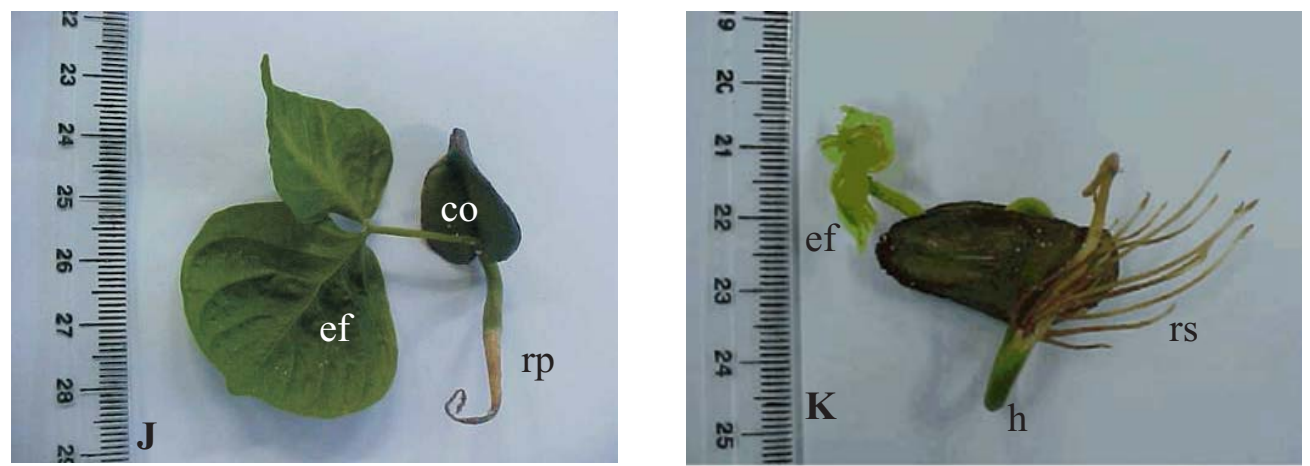

FIGURA 2. Caracterização morfológica do fruto, semente, germinação e plântulas de Cedrelinga catenaeformis Ducke. A-fruto desidratado; $\mathrm{B}$ - aspectos da semente hidratada; $\mathrm{C}$ - detalhe da superfície e bordo da semente; $\mathrm{D}$ - detalhe do funículo e região hilar; $\mathbf{E}$ - embrião em corte longitudinal; $\mathbf{F}$-cotilédones em corte transversal; $\mathbf{G}$-alongamento da raiz primária, liberação dos cotilédones; $\mathbf{H}$ - detalhe do coleto; $I$ - plântula normal; $J, K$-plântulas anormais. rp - raiz primária; rs - raiz secundária; cl-coleto; $h$ - hipocótilo; ep-epicótilo; $r d$ - radícula; co-cotilédones; pl-plúmula; ef-eófilos.

levemente canaliculado, recoberto por tricomas simples, curtos, curvos, hialinos e ápice espesso. Eófilos dois, compostos, opostos, bifoliolados; folíolos cartáceos, subsésseis, oval-elípticos, com ápice de acuminado a levemente caudado, margem inteira, base assimétrica, falcada, face adaxial pulverulenta e face abaxial pubérula; venação broquidódroma, com nervura principal pubérula em ambas as faces (Figura 3). Raque canaliculada, subalada, verde, com tricomas semelhantes aos encontrados no epicótilo, apresentando no ápice da face dorsal uma estipela, de coloração 
verde e uma glândula de ovóide a suborbicular na face ventral entre os primeiros pares de folíolos (Figura 3). O segundo eófilo surgiu em torno de 95 dias, após a semeadura.

Morfologia da plântula anormal - nos testes de germinação com sementes de cedrorana, em laboratório, verificou-se a ocorrência de plântulas anormais (Figuras 2J, $\mathrm{K}$ ), que apresentaram raiz primária de tamanho normal, com pequenas lesões ao longo do seu comprimento ou, às vezes, de tamanho reduzido e deteriorada no ápice (Figura 2J); raízes secundárias mais longas do que a raiz principal, espessas quando comparadas com as raízes de uma plântula normal (Figura 2K). Hipocótilo e epicótilos aparentemente normais, porém com cotilédones parcialmente fechados e envolvidos pelo tegumento da semente (Figura 2K). Observou-se também raque com folíolos de tamanho e morfologia diferentes (heterofilia), além da ausência de epicótilo, conforme mostra a figura $2 \mathrm{~J}$. As plântulas anormais permaneceram viáveis durante o processo germinativo até 70 dias, após a semeadura.

Os frutos de C. catenaeformis são facilmente observados na floresta Amazônica, apresentam-se em cadeias compridas, geralmente, composta por seis segmentos (legumes) planos e contorcidos. De acordo com Ducke (1949), C. catenaeformis apresenta uma das maiores árvores amazônicas, em comprimento e diâmetro do tronco, com aspecto semelhante aos cedros, por isso a denominação vulgar mais usada é cedrorana.

Os caracteres morfológicos dos frutos de leguminosae têm sido em geral reconhecidos como um caráter de grande importância nos estudos taxonômicos (Lima, 1985; Barroso et al., 1999). Barroso et al. (1999) afirmam que os caracteres de frutos e, algumas vezes, de sementes são decisivos na identificação dos táxons.

A variação morfológica dos tipos de frutos dentro da família Leguminosae foi confirmada por Oliveira (1997). Segundo a autora, das 30 espécies estudadas $33,4 \%$ pertencem aos legumes e $23,3 \%$ a sâmaras. Outros tipos de frutos estavam presentes em 3,3\%, como o folículo em Swartzia langsdorfii Raddi, 33,4\% na variação de legume como o legume bacóide em Holocalyx balansae Mich., e craspédio em Mimosa caesalpiniaefolia Benth.

As espécies estudadas apresentaram legumes samaróides com variação de $9-12 \mathrm{~cm}$ em $C$. catenaeformis e 17,0-29,5cm de comprimento em $D$. excelsa, enquanto que as sementes variaram de $2,4-3,9 \mathrm{~cm}$ de comprimento em $C$. catenaeformis e 1,1-1,5cm de comprimento em $D$. excelsa. As comparações das dimensões de frutos e sementes, deste estudo, não diferiram com as encontradas na literatura consultada. Os resultados confirmam e complementam as poucas informações existentes descritas por Roosmalen (1985) e Ducke (1949), para $C$. catenaeformis, e por Gunn (1984) e Lima (1985), para $D$. excelsa.

Em relação à estrutura seminal, as informações das espécies são praticamente inexistentes, poucas são as literaturas que tratam dos aspectos morfológicos das sementes.

A semente de C. catenaeformis apresenta testa de consistência membranácea, facilmente permeável para Polhill et al. (1981), esporadicamente, sementes que não são rígidas têm adaptação à necessidade de uma rápida germinação em ambientes florestais ou transfere o papel de proteção para o pericarpo e, nesse caso, os traços característicos das sementes rígidas são ausentes ou vestigiais. Esse fato foi confirmado, nesse estudo, durante a coleta dos frutos da árvore matriz, onde foi observado um grande número de sementes germinadas, ainda envolvidas pelo pericarpo.

O endosperma, nas sementes estudadas, está presente apenas em $D$. excelsa e encontra-se no lado externo dos cotilédones, envolvendo-os totalmente, é de consistência dura e de aspecto opaco em sementes desidratadas, tornando-se gelatinoso quando em contato com a água. Para Gunn (1984), as sementes filogeneticamente mais primitivas apresentam mais endosperma do que as sementes mais evoluídas.

Os embriões apresentaram cotilédones carnosos ou foliáceos, plano-convexos, com lobos bem marcados, entre os quais se articula o eixo hipocótilo-radícula reto. A plúmula apresenta-se rudimentar em $D$. excelsa e bem desenvolvida em C. catenaeformis. Segundo Barroso et al. (1999) e Gunn (1984), a plúmula nas espécies de Leguminosae pode apresentar-se rudimentar, quando os segmentos não são bem diferenciados, moderadamente desenvolvida quando apresentam segmentos em desenvolvimento e desenvolvidas quando apresentam os segmentos bem diferenciados em pinas.

Quanto à morfologia das plântulas relacionadas ao tipo de germinação, ambas as espécies apresentaram germinação do tipo epígea e fanerocotiledonar. Como não existe unanimidade em relação aos critérios adotados pelos autores, o presente trabalho baseou-se na terminologia utilizada por Ducke (1965), que reconheceu o termo criptocotiledonar para a germinação onde os cotilédones permanecem dentro dos envoltórios da semente e fanerocotiledonar quando ocorre a liberação dos cotilédones. A presença do hipocótilo ascendente eleva os cotilédones acima do solo, classificando a germinação como do tipo epígea.

Em relação ao processo germinativo, Beltrati (1992) considera que "os estádios de plântulas e indivíduos jovens, fases críticas no ciclo de vida da planta, são as etapas mais 


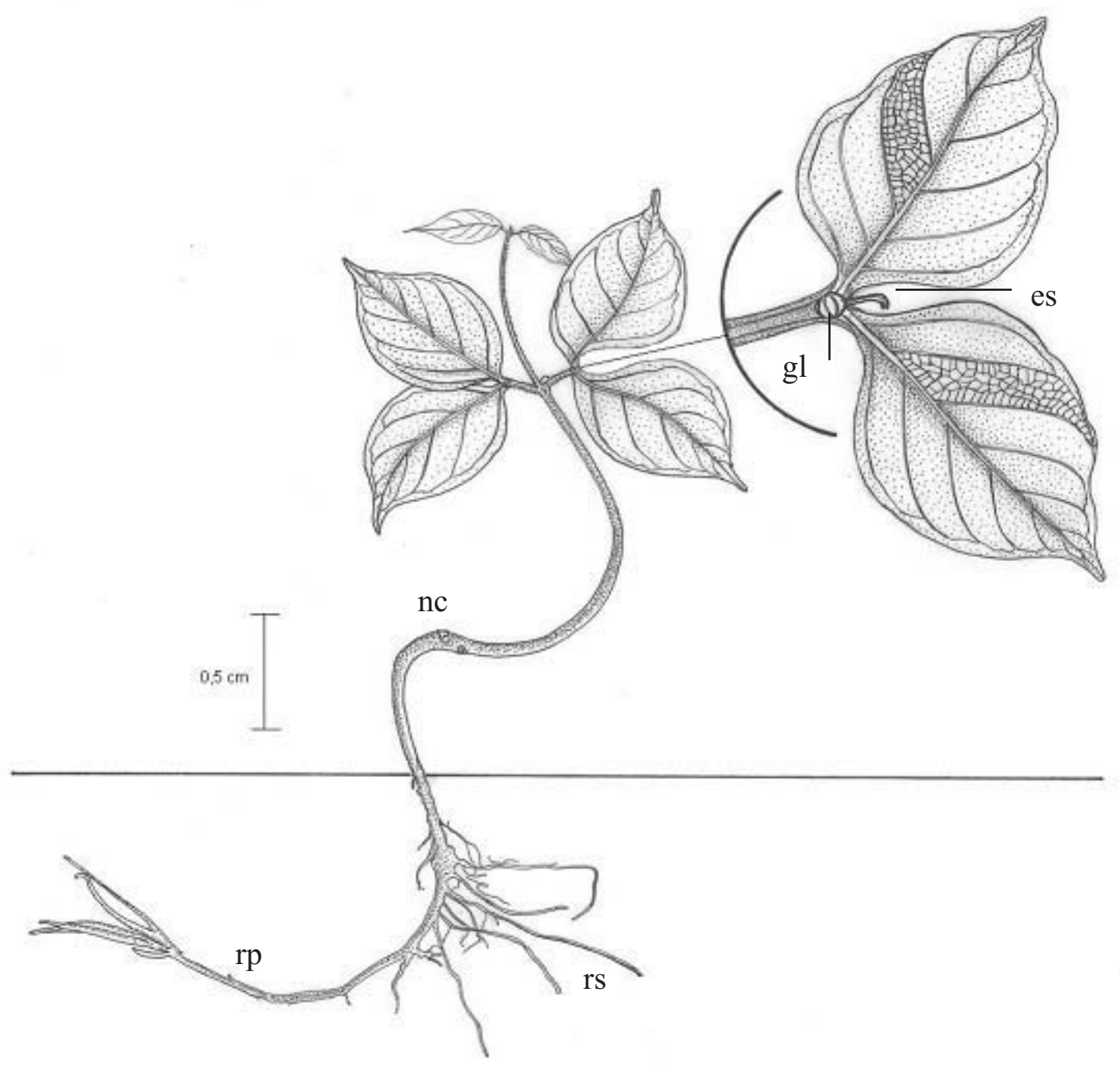

FIGURA 3. Plântula juvenil de Cedrelinga catenaeformis Ducke, após a queda dos cotilédones. Legenda: es - estipela; gl - glândula; nc-nó cotiledonar; rp-raiz primária; rs - raiz secundária.

sensíveis a perturbações induzidas pelo homem, mudanças climáticas, competição intra e interespecífica, entre outros fatores que podem provocar redução ou extermínio dos bancos de germoplasma". Dentro desse contexto, o presente estudo observou comportamento anormal durante o processo germinativo em $C$. catenaeformis. As sementes estudadas dessa espécie, apresentaram anormalidades ou pequenos defeitos, conforme o critério utilizado por Brasil (1992). As plântulas anormais encontradas nos testes de germinação de C. catenaeformis apresentaram plântulas com raiz primária deteriorada, raízes secundárias com características anormais, ausência de epicótilo e plântulas com heterofilia. Plântulas anormais foram também encontradas em Cedrela odorata L. (Meliaceae), apresentando radícula e raiz deterioradas nos primeiros dias do desenvolvimento ou plântulas aparentemente normais porém com sistema radicular truncado e em deterioração (Andrade e Pereira, 1994). O surgimento de plântulas anormais em C. catenaeformis (cedrorana) podem estar, provavelmente, correlacionado com a pequena população no local de coleta e por esta razão, possivelmente ocorreram altas taxas de "inbreeding".

\section{CONCLUSÕES}

Os frutos de $C$. catenaeformis e $D$. excelsa são legumes samaróides e longos. D. excelsa tem $20 \mathrm{~cm}$ de comprimento em média, contendo até 10 sementes por fruto; $C$. cateanaeformis possui em média de $10,3 \mathrm{~cm}$ de comprimento e apresenta apenas uma semente em cada segmento.

As sementes são suborbiculares, com bordo irregular 
em C. catenaeformis e oblongas e achatadas em D. excelsa .

Ambas as espécies apresentam germinação do tipo epígea e fanerocotiledonar.

As plântulas de C. catenaeformis caracterizam-se pelos eófilos bifoliolados, opostos, ovais, com ápice acuminado e uma glândula ovóide entre os primeiros folíolos, enquanto $D$. excelsa apresenta eófilos pinados, opostos, com 7-8 pares de folíolos oblongos e base assimétrica.

\section{AGRADECIMENTOS}

As autoras agradecem à Fernanda Ilkiu Borges e Michele B. Pinto pela ajuda nas fotografias e sugestões utilizadas neste trabalho e a FAPEAM pelo financiamento do projeto.

\section{REFERÊNCIAS}

ANDRADE, A.C.S.; PEREIRA, T. Efeito do substrato e da temperatura na germinação e no vigor de sementes de cedro Cedrela odorata L. (Meliaceae). Revista Brasileira de Sementes, Brasília, v.16, n.1, p.34-40, 1994

ANDRADE, V.M.M.; DAMIÃO FILHO, C.F. Morfologia vegetal. Jaboticabal: FUNEP, 1989. 59p.

BARROSO, G.M.; AMORIM, M.P.; PEIXOTO, A.L.; ICHASO, C.L.F. Frutos e sementes. Morfologia aplicada à sistemática de dicotiledôneas. Viçosa: UFV, 1999. 443p.

BELTRATI, C.M. Morfologia e anatomia de sementes. Rio Claro: UNESP, 1992. p.1-106. (Apostila do curso de Pós-graduação em Ciências Biológicas, Área de Biologia Vegetal).

BRASIL. Ministério da Agricultura e Reforma Agrária. Regras para análise de sementes. Brasília: SNDA/DNDV/CLAV, 1992. $365 \mathrm{p}$.

CARVAlho, N.M.; NAKAGAVA, J. Sementes: ciência, tecnologia e produção. 3.ed. Campinas: Fundação Cargil, 1988. 424p.

DUCKE, A. Notas da flora neotrópica - II. As leguminosas da Amazônia brasileira. 2.ed. Boletim Técnico do Instituto Agronômico do Norte. Belém, n.18, p.48-65, 1949.

DUKE, J.A. Keys for the identificacion of seedlings of some preeminent wood species in eight forest types in Puerto Rico. Annals of the Missouri Botanical Garden, Columbus, v.52, n.3, p.314-350, 1965.

FERRAZ, I.D.K. Germinação e armazenamento de sementes florestais de interesse econômico na Amazônia: problemas e necessidades de atuação. In: VAL, A.L.; FIGLIUOLO, R.; FELBERG,
E. (ed.). Bases científicas para estratégias de preservação e desenvolvimento da Amazônia: fatos e perspectivas. Manaus: INPA, 1991. v.1, p.225-229.

GUNN, C.R. Fruits and seeds of genera in the subfamily Mimosoideae (Fabaceae). Beltsville: United State-Departament of Agriculture, 1984. 193p. (Technical Bulletim, 1681).

HICKEY, L.J. Classification of the architecture of dicotyledonous leaves. American Journal of Botany, Washington, v.60, n.1, p.1733, 1973.

LIMA, M.P.M. Morfologia dos frutos e sementes dos gêneros da tribo Mimoseae (Leguminosae-Mimosoideae) aplicada à sistemática. Rodriguesia, Rio de Janeiro, v.37, n.62, p.53-78, 1985.

LOUREIRO, A.A.; SILVA, M.F.; ALENCAR, J.C. Essências madeireiras da Amazônia. Manaus: INPA/SUFRAMA, U.A, 1979. $245 \mathrm{p}$.

OLIVEIRA, E.C. Morfologia de plântulas. In: PINÃ RODRIGUES, F.C.M. (Coord.). Manual de análise de sementes florestais. Campinas: Fundação Cargill, 1988. p.15-24.

OLIVEIRA, E.C. Morfologia de plântulas florestais. In: AGUIAR, I.B.; PIÑA-RODRIGUES, F.C.M.; FIGLIOLIA, M.B. (Coord.). Sementes florestais tropicais. Brasília: ABRATES, 1993. p.175214.

OLIVEIRA, D.M.T. Análise morfológica comparativa de frutos, sementes, plântulas e plantas jovens de 30 espécies arbóreas de Fabaceae ocorrentes no estado de São Paulo. 1997. 211f. Tese (Doutorado em Biologia Vegetal) - Instituto de Biociências do Campus de Rio Claro, Universidade Estadual Paulista, Rio Claro, 1997.

POLHILL, R.M.; RAVEN, P.H.; STIRTON, C.H. Evolution and systematics of the Leguminosae. In: POLHILL, R.M.; RAVEN, P.H. (Ed.) Advances in legume systematics. London: Richmond, Surrey, 1981. pt.1, p.1-25.

ROOSMALEN, M.G.M. Fruits of the Guianan Flora. Wageningen: Silvicultural Department of the Wageningen Agricultural University, 1985. 483p.

STEARN, W.T. Descriptive terminology. In: Botanical Latin: Hafner Publishing Company, 1983. p.311-57.

RIZZINI, C.T. Experimental studies on seedlings development of cerrado woody plants. Annals of the Missouri Botanical Garden, St. Louis, v.52, n.3, p.410-426, 1965.

VASTANO JR., B.; BARBOSA, A.P.; GONÇALVES, A.N. Tratamentos pré-germinativos de sementes de espécies de sementes florestais amazônicas. I. Angelim-pedra (Dinizia excelsa Ducke-Leguminosae-Mimosoideae). Acta Amazônica, Manaus, v.13, n.2, p.413-419, 1983.

VOGEL, E.F. Seedlings of dicotyledons. Wageningen: Pudoc, 1980. $471 \mathrm{p}$. 